\title{
Alexithymia and Acne Vulgaris: A Case Control Study
}

\author{
Didem Sunay ${ }^{\circledR}{ }^{凶}$ Murat Baykir²$^{2}$, Gülfem Ateş ${ }^{2}$ and Meral Ekşioğlu² \\ ${ }^{1}$ Department of Dermatology, Ministry of Health, Ankara Training and Research Hospital, Ankara, Turkey \\ ${ }^{2}$ Ministry of Health, Ankara Training and Research Hospital, Clinic of Dermatology, Ankara, Turkey
}

\begin{abstract}
Objective To assess relationship between alexithymia and acne vulgaris in young people.
Methods A hundred and eleven subjects between 15 and 25 years of age referred to out-patient clinic of dermatology with acne and 78 subjects applied to family physician for complaints other than acne were included in patient and control groups of the study, respectively. A questionnaire to determine demographic characteristics, an acne classification to determine severity of acne and Toronto Alexithymic Scale (TAS) to assess alexithymia were used.

Results The mean scores of TAS were $52.7 \pm 10.8$ and $51.7 \pm 10.7$ in patient and control groups, respectively. Alexitymia was determined in $23.4 \%$ of the subjects in acne group and in $24.4 \%$ of control group. No significant differences were found between groups in terms of alexithymia, intermediate alexitymia and three-factors of TAS.
\end{abstract}

Conclusion Alexithymia does not appear to be related to acne vulgaris.

Psychiatry Investig 2011;8:327-333

Key Words Acne vulgaris, Alexithymia, Young people.

\section{INTRODUCTION}

There is a considerable literature concerning skin disease and psychological morbidity, and the consensus of opinion has long been that skin diseases are strongly associated with psychological illness and psychological distress. ${ }^{1,2}$ The relationship between psychic situation and skin diseases was grouped as follows; 1) Physical complaint is primarily a sign of emotional disorder; 2) Organic skin lesion impairs psychological status of the individual; 3) Both organic, and emotional factors interact in different periods, leading to symptoms and disease. ${ }^{3}$

In recent years, researchs have demonstrated that stress, mood and anxiety disorders, social support and personality traits are the psychological factors that associated with dermatological diseases. ${ }^{3}$ Alexithymia is a personality trait characterized by reduced symbolic thinking, a poor fantasy life, and a limited ability to identify and verbally express emotions. ${ }^{4}$ In-

Received: April 20, 2011 Revised: May 14,2011

Accepted: June 2, 2011 Available online: November 3, 2011

$\triangle$ Correspondence: Didem Sunay

Kız kulesi sokak 3/5 Gaziosmanpasa Çankaya, 06450, Ankara-Turkey

Tel: +90-312-595-4247, Fax: +90-312-319-6491

E-mail: didemsunay@gmail.com

(a) This is an Open Access article distributed under the terms of the Creative Commons Attribution Non-Commercial License (http://creativecommons.org/licenses/by$\mathrm{nc} / 3.0$ ) which permits unrestricted non-commercial use, distribution, and reproduction in any medium, provided the original work is properly cited. terest in alexithymia has increased considerably over the past decade. Recent research has suggested that alexi-thymia can be considered as one of several possible risk factors for a variety of medical and psychiatric disorders, as it may increase susceptibility to the development of a variety of diseases in addition to genetic determinants and emotional stress. ${ }^{5}$ Hence, it is not surprising that alexithymic individuals, who fail to cope with stress and have difficulties in communicating their feelings, are at risk of the development of certain specific dermatologic diseases. Because of their alexithymic features, they tend to develop fewer close relationships and less social skills, and this social incompetence may also adversely affect their health and general well-being. ${ }^{6.7}$ Data suggest that screening for alexithymia may also be useful in order to reveal the role of emotional dysregulation as a triggering factor in some patients with chronic skin diseases. ${ }^{5}$

The dermatological conditions most commonly and consistently found to be associated with psychiatric or psychological morbidity are psoriasis, ${ }^{1,8}$ acne ${ }^{1,8}$ and atopic eczema. ${ }^{8,9}$ Acne is the most common problem that presents to dermatologists. Because it causes visible disfiguring of the face, it produces a great deal of embarrassment, frustration, anger, and depression in patients. In addition, acne is most common in adolescence and young adulthood, a time when patients are least capable of coping with additional stress. As a result, it is virtually impossible to separate acne and psychiatric disturbances. ${ }^{10}$ 
Thus, in the present study we aimed to establish whether there was a relationship between acne vulgaris and alexithymia in young people.

\section{METHODS}

\section{Study design}

The study was a case-control study that conducted bet-ween January 2010 and May 2010 in dermatology and family medicine departments of a state hospital at the city center of Ankara. The study was granted ethical approval by institutional ethical committee.

\section{Participants}

The subjects referred to out-patient clinic of dermatology with acne, between 15 and 25 years of age were included in the study. Exclusion criteria for the patient group were as follows: cognitive impairment, acne considered by the physician to be secondary to other medications (systemic steroids, therapeutic androgens, etc.), other skin diseases associated with acne, diagnosed psychiatric disease.

The control group of the study was consisted of participants applied to family physician for complaints other than acne, at the same range of age. Exclusion criteria for the control group were as follows: cognitive impairment, having any skin diseases including acne, diagnosed psychiatric disease.

All participants were informed about study and written consents were taken.

\section{Methods}

\section{Questionnaire}

A self-reported questionnaire consisted of the following parts; demographic data about the subjects and their families, medical history, smoking and alcohol consumption, was used.

\section{Objective Acne Assessment}

Participants were examined for the presence of acne by a dermatologist according to acne classification developed by Hayashi et al. ${ }^{11}$ Inflammatory eruptions (open and closed comedones, papules, pustules, cysts and nodules) on half of the face were counted. Inflammatory acne was considered 'mild' if the number of lesions were 0-5, 'moderate' if 6-20, 'severe' if 21-50, 'very severe' if more than 50 . In the presence of nodules and cysts it was considered 'severe' regardless of the number of inflammatory lesions and 'very severe' if the number of nodules and cysts were more than three. If there was cysts and nodules besides inflammatory comedones, classification was made according to the number of these lesions. Participants with only comedones were accepted as 'mild' acne.

\section{Toronto Alexithymic Scale (TAS)}

The Turkish version of Toronto Alexithymic Scale (TAS-20), the most frequently used questionnaire for measuring alexithymia, was used. ${ }^{12,13}$ TAS-20 is a 20 -item self-report scale with a three-factor structure congruent with the alexithymia construct: difficulty in identifying feelings (DIF), difficulty in describing feelings (DDF), and externally oriented thinking (EOT). Each item is rated on a five-point Likert scale ranging from 1 (strongly disagree) to 5 (strongly agree), with five items negatively keyed. The TAS-20 score ranges from 20 to 100; subjects scoring 61 or more have been suggested to be alexithymic, whereas those scoring 51 or less are considered to be non alexithymic. Those that obtain a score between 52 and 60 have been suggested to be intermediate alexithymic.

\section{Statistics}

Data were analyzed by using SPSS (Statistical Program for Social Sciences) version 12. Definitive statistics were expressed as mean \pm standard deviation for continuously measured variables, and as case number and (\%) for nominal variables. Chi Square test was used for comparing the groups. A p value of 0.05 was considered significant.

\section{RESULTS}

Since the study based on voluntary participation, it was completed with 111 participants in patient and 78 participants in control group. The mean ages of the subjects were similar and, 18.3 \pm 2.6 years and $17.7 \pm 2.8$ years in patient and control groups, respectively $(\mathrm{p}=0.128)$. Demographic characteristics of the groups were shown in Table 1.

The severity of acne was mild in $23.4 \%$, moderate in $41.4 \%$, severe in $28.8 \%$ and very severe in $6.3 \%$ of the patients. Sixty one subjects $(55 \%)$ in patient group had received treatment for acne, previously. The type of treatment was topical in $55.6 \%$, oral in $6.3 \%$, and topical and oral in $38.1 \%$ of them.

The mean scores of TAS were $52.7 \pm 10.8$ and $51.7 \pm 10.7$ in patient and control groups, respectively. Alexitymia was determined in $23.4 \%$ of the subjects in acne group and in $24.4 \%$ of the control group, and no significant difference was found between groups ( $\mathrm{p}=1.00)$. There were also no statistically significant differences between groups in terms of intermediate alexitymia and three-factors of TAS; DIF, DDF and EOT (Table 2). In patient group the relation between alexithymia, intermediate alexithymia and severity of acne was assessed and no statistically significant relation was found (Table 3 ). When the participants with alexithymia and without alexithymia compared in terms of age, gender, education, parental education and monthly income of the family, no statistically significant differences were found between groups (Table 4). 


\section{DISCUSSION}

The alexithymia construct is composed of four major fac- tors; 1) difficulty in identifying feelings and distinguishing between feelings and the bodily sensations of emotional arousal; 2) difficulty in describing feelings to other people; 3) con-

Table 1. Demographic characteristics of groups

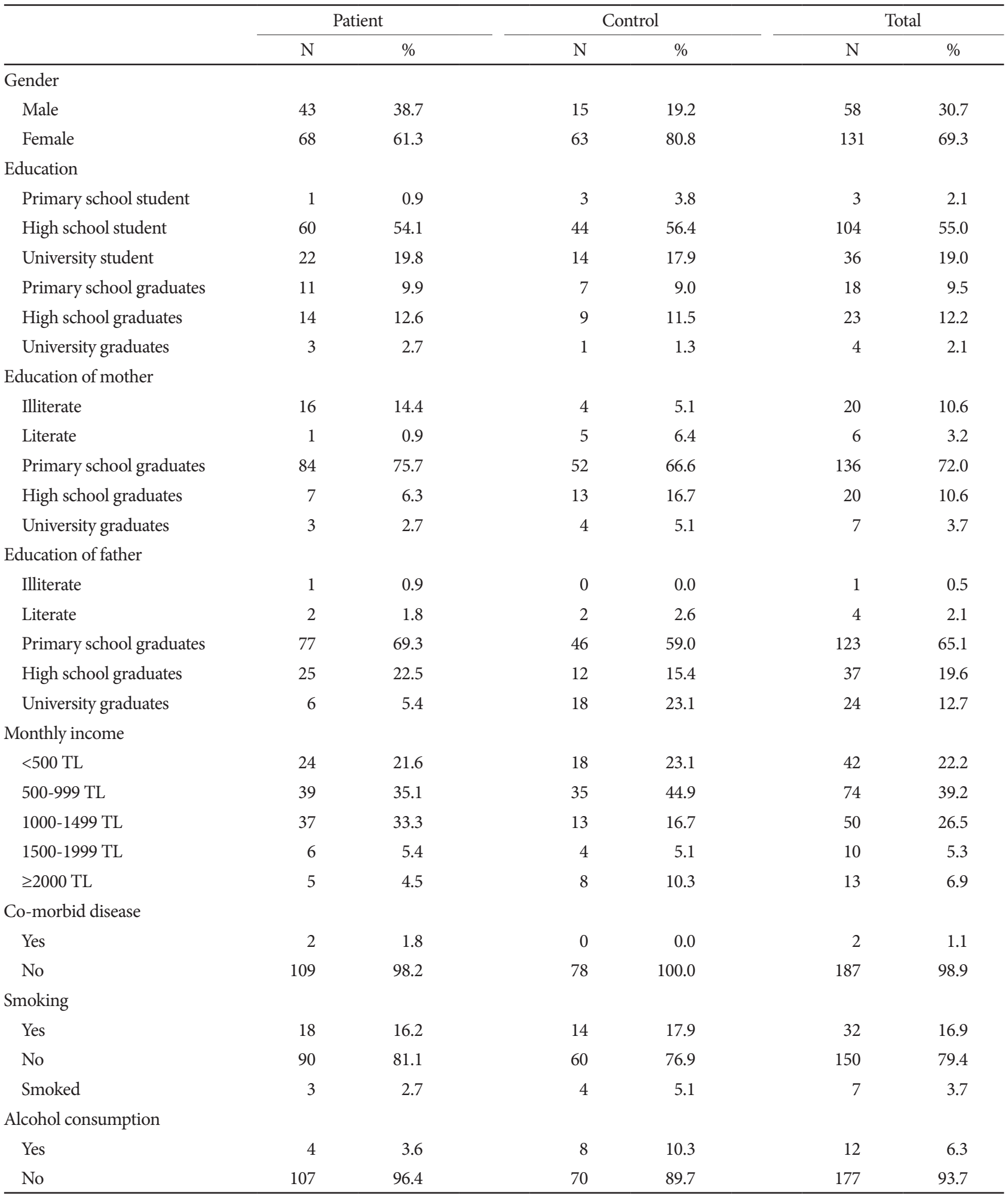

TL: Turkish Liras 
Table 2. Comparison of the groups according to TAS-20

\begin{tabular}{|c|c|c|c|c|c|}
\hline & & Patient, N (\%) & Control, N (\%) & Total, N (\%) & $\mathrm{p}$ \\
\hline \multirow[t]{2}{*}{ Alexithymia } & No & $85(76.6)$ & $59(75.6)$ & $144(76.2)$ & 1 \\
\hline & Yes & $26(23.4)$ & $19(24.4)$ & $45(23.8)$ & \\
\hline \multirow[t]{2}{*}{ Intermediate alexithymia } & No & $76(68.5)$ & $55(70.5)$ & $131(69.3)$ & 0.888 \\
\hline & Yes & $35(31.5)$ & $23(29.5)$ & $58(30.7)$ & \\
\hline \multirow[t]{2}{*}{ DIF } & No & $77(69.4)$ & $57(73.1)$ & $134(70.9)$ & 0.696 \\
\hline & Yes & $34(30.6)$ & $21(26.9)$ & $55(29.1)$ & \\
\hline \multirow[t]{2}{*}{$\mathrm{DDF}$} & No & $79(71.2)$ & $60(76.9)$ & $139(73.5)$ & 0.474 \\
\hline & Yes & $32(28.8)$ & $18(23.1)$ & $50(26.5)$ & \\
\hline \multirow[t]{2}{*}{ EOT } & No & $83(74.8)$ & $60(76.9)$ & $143(75.7)$ & 0.734 \\
\hline & Yes & $28(25.2)$ & $18(23.1)$ & $46(24.3)$ & \\
\hline
\end{tabular}

DIF: difficulty in identifying feelings, DDF: difficulty in describing feelings, EOT: externally oriented thinking, TAS-20: Toronto Alexithymia Scale-20

Table 3. The relation between alexithymia, intermediate alexithymia and severity of acne in patient group

\begin{tabular}{|c|c|c|c|c|c|c|c|c|}
\hline & \multicolumn{4}{|c|}{ Alexithymia, N (\%) } & \multicolumn{4}{|c|}{ Intemediate alexithymia, $\mathrm{N}(\%)$} \\
\hline & No & Yes & Total & $\mathrm{p}$ & No & Yes & Total & $\mathrm{p}$ \\
\hline Duration of acne & & & & - & & & & - \\
\hline$<1$ month & $6(7.1)$ & $0(0.0)$ & $6(5.4)$ & & $3(3.9)$ & $3(8.6)$ & $6(5.4)$ & \\
\hline 1-6 months & $7(8.2)$ & $3(11.5)$ & $10(9.0)$ & & $7(9.2)$ & $3(8.6)$ & $10(9.0)$ & \\
\hline 7-12 months & $12(14.1)$ & $6(23.1)$ & $18(16.2)$ & & $12(15.8)$ & $6(17.1)$ & $18(16.2)$ & \\
\hline$>12$ months & $60(70.6)$ & $17(65.4)$ & $77(69.4)$ & & $54(71.1)$ & $23(65.7)$ & $77(69.4)$ & \\
\hline Severity of acne & & & & 0.607 & & & & - \\
\hline Mild & $21(24.7)$ & $5(19.2)$ & $26(23.4)$ & & $19(25.0)$ & $7(20.0)$ & $26(23.4)$ & \\
\hline Moderate & $37(43.5)$ & $9(34.6)$ & $46(41.4)$ & & $32(42.1)$ & $14(40.0)$ & $46(41.4)$ & \\
\hline Severe & $22(25.9)$ & $10(38.5)$ & $32(28.8)$ & & $20(26.3)$ & $12(34.3)$ & $32(28.8)$ & \\
\hline Very severe & $5(5.9)$ & $2(7.7)$ & $7(6.3)$ & & $5(6.6)$ & $2(5.7)$ & $7(6.3)$ & \\
\hline Total & $85(100.0)$ & $26(100.0)$ & $111(100.0)$ & & $76(100.0)$ & $35(100.0)$ & $111(100.0)$ & \\
\hline
\end{tabular}

stricted imaginative processes, as evidenced by a pausity of fantasies; and 4) a stimulus-bound, externally oriented cognitive style. ${ }^{14}$ The characteristic failure of alexithymic people to regulate distressing emotions may result in exacerbated responses in the autonomic and neuroendocrine system, producing a range of somatic diseases. Several researchers have attempted to identify the physiologic pathways leading to disease in alexithymia, but the findings have been inconsistent. ${ }^{15}$ Some research data have revealed higher baseline levels of sympathetic activity in alexithymic individuals, leading to higher heart rate, higher electrodermal activity, and lower oxygen consumption. ${ }^{16}$ Alexithymia also seems to be associated with an impaired immune response. ${ }^{17,18}$

Although researchs of alexithymia in dermatology are still scarce and reveal conflicting results, preliminary data show that alexithymia seems to be associated with some skin diseases. Arck et al. ${ }^{19}$ have reviewed the resent research offering solid evidence for a local neuroendocrine skin axis that oper- ates as an important "brain-skin" connection. The skin and its appendages are capable of generating the same mediators that are used during systemic stress responses, and they have established a fully functional peripheral equivalent of the systemic, stres-activated hypothalamic-pituitary-adrenal axis. ${ }^{20,21}$ Hence, it is not surprising that alexithymic individuals, who fail to cope with stress are at risk of the development of specific dermatologic diseases. Among dermatologic diseases psoriasis is the most common disease that researchers were interested in exploring the relationship between alexithymia. The association of alexithymia and psoriasis was revealed in many studies ${ }^{4,22-24}$ whereas other studies failed to demonstrate a significant difference in alexithymic scores between patients with psoriasis and healthy controls. ${ }^{3,14,25}$

The prevalence of alexithymia in patients suffering from alopecia areata was also assessed by several authors and TAS scores of patients with alopecia areata were found significantly higher than those of controls. ${ }^{26-28}$ 
Table 4. Comparison of participants with alexithymia and without alexithymia according to demographic characteristics

\begin{tabular}{|c|c|c|c|c|}
\hline & No alexithymia, N (\%) & Alexithymia, N (\%) & Total, N (\%) & $\mathrm{p}$ \\
\hline \multicolumn{5}{|l|}{ Age (year) } \\
\hline $15-16$ & $51(73.9)$ & $18(26.1)$ & $69(100.0)$ & \multirow{3}{*}{0.751} \\
\hline $17-18$ & $43(75.4)$ & $14(24.6)$ & $57(100.0)$ & \\
\hline $19-25$ & $50(79.4)$ & $13(20.6)$ & $63(100.0)$ & \\
\hline \multicolumn{5}{|l|}{ Gender } \\
\hline Male & $43(74.1)$ & $15(25.9)$ & $58(100.0)$ & \\
\hline Female & $101(77.1)$ & $30(22.9)$ & $131(100.0)$ & \\
\hline \multicolumn{5}{|l|}{ Education } \\
\hline Primary school graduates & $93(73.8)$ & $33(26.2)$ & $126(100.0)$ & \multirow{3}{*}{0.798} \\
\hline High school graduates & $47(79.7)$ & $12(20.3)$ & $59(100.0)$ & \\
\hline University graduates & $4(100.0)$ & $0(0.0)$ & $4(100.0)$ & \\
\hline \multicolumn{5}{|l|}{ Education of mother } \\
\hline Illiterate/Literate & $18(69.2)$ & $8(30.8)$ & $26(100.0)$ & \multirow{4}{*}{0.522} \\
\hline Primary school graduates & $103(75.7)$ & $33(24.3)$ & $136(100.0)$ & \\
\hline High school graduates & $16(80.0)$ & $4(20,0)$ & $20(100.0)$ & \\
\hline University graduates & $5(71.4)$ & $2(28.6)$ & $7(100.0)$ & \\
\hline \multicolumn{5}{|l|}{ Education of father } \\
\hline Illiterate/Literate & $3(60.0)$ & $2(40.0)$ & $5(100.0)$ & \multirow{4}{*}{0.459} \\
\hline Primary school graduates & $90(73.2)$ & $33(26.8)$ & $123(100.0)$ & \\
\hline High school graduates & $31(83.8)$ & $6(16.2)$ & $37(100.0)$ & \\
\hline University graduates & $18(75.0)$ & $6(25.0)$ & $24(100.0)$ & \\
\hline \multicolumn{5}{|l|}{ Monthly income } \\
\hline$<500 \mathrm{TL}$ & $28(66.7)$ & $14(33.3)$ & $42(100.0)$ & \multirow{5}{*}{0.279} \\
\hline 500-999 TL & $56(75.7)$ & $18(24.3)$ & $74(100.0)$ & \\
\hline $1,000-1,499 \mathrm{TL}$ & $42(84.0)$ & $8(16.0)$ & $50(100.0)$ & \\
\hline$\geq 1,500 \mathrm{TL}$ & $18(78.3)$ & $5(21.7)$ & $23(100.0)$ & \\
\hline Total & $144(76.2)$ & $45(23.8)$ & $189(100.0)$ & \\
\hline
\end{tabular}

TL: Turkish Liras

Vitiligo is another dermatologic disease that the relation between alexithymia was investigated. The data of Picardi et al. ${ }^{29}$ showed that patients with vitiligo scored significantly higher than controls on TAS-20, and the number of patients classified as alexithymic or borderline alexithymic was almost two fold higher in the vitiligo group.

However, until today no studies carried out on the association of alexithymia and acne vulgaris. Acne is the most common problem that presents dermatologists. It commonly affects young people at a time when they are undergoing maximum psychological, social and physical changes. Smithard et al. ${ }^{30}$ studied 317 students between 14-16years of age and found that those with acne were more likely to score in the abnormal/borderline range for emotional or behavioral symptoms. Do et al. ${ }^{31}$ reported in their study that adolescents with definite acne had significantly high-score self-perceived severity, stress, and disturbances in interpersonal relationships and daily life. Kubota et al. ${ }^{32}$ found that students with acne were significantly more depressed than those without acne. In a cross-sectional study by Magin et al. ${ }^{33}$ it was found that 'non-psychiatric diagnosis' psychological morbidity-embarrassment, shame, self-consciousness, impairments of selfimage, self-confidence and self-esteem, anger, and stigmatization-were more prominent than symptoms of anxiety and depression in patients with acne, psoriasis and atopic dermatitis.

In the present study we aimed to establish whether acne vulgaris was related with alexithymia in other words whether prevalence of acne vulgaris was high in alexitymic individuals, however our results did not demonstrate a link between the two conditions. Perhaps the most striking result of our study was the high alexithymia and intermediate alexithymia rates in individuals between $15-25$ years of age (23.8\% and $30.7 \%$, respectively) with or without acne. The prevalence of alexithymia has been found to be $10-13 \%$ in general popula- 
tion samples. ${ }^{34}$ Montreuil et al. ${ }^{35}$ reported the rate of alexithymia in their study with 773 students, as $6.8 \%$. Similar with our results, Moriguchi et al. ${ }^{36}$ found that the TAS-20 total, DIF and DDF scores were high for teenagers. They also found that the scores decrease with age, in particular, from age 30 did not change significantly. As conclusion they suggested that younger people are cognitively less capable of looking into their inner emotional states, and identifying them. They also suggested that personal insight seems to be acquired with maturity, and reaches its full potential in one's thirties. Thus, skin diseases affecting patients during childhood and/ or adolescence (such as acne and atopic eczema, and some psoriasis) may be proposed to have a significant effect during the formation of personality traits. ${ }^{33}$

Limitations of the present study were small sample size, age limitation and conducting at one center. Further multicenter studies with larger study groups and different age ranges may provide definite results.

\section{Conclusion}

We did not find any relationship between acne and alexithymia. However we thought that high alexithymia rates in this age group needs further investigation.

\section{REFERENCES}

1. Hughes JE, Barraclough BM, Hamblin LG, White JE. Psychiatric symptoms in dermatology patients. Br J Psychiatry 1983;143:51-54.

2. Fried RG, Gupta MA, Gupta AK. Depression and skin disease. Dermatol Clin 2005;23:657-664.

3. Güz H, Ay M, Dilbaz N. Bir grup dermatolojik hastada aleksitimi, depresyon ve anksiyete. J Psychiatry Neurol Sci 2001;14:99-103.

4. Picardi A, Mazzotti E, Gaetano P, Cattaruzza MS, Baliva G, Melchi CF, et al. Stress, social support, emotional regulation, and exacerbation of diffuse plaque psoriasis. Psychosomatics 2005;46:556-564.

5. Willemsen R, Roseeuw D, Vanderlinden J. Alexithymia and dermatology: the state of art. Int J Dermatol 2008;47:903-910.

6. Picardi A, Porcelli P, Mazzotti E, Fassone G, Lega I, Ramieri L, et al. Alexithymia and global psychosocial functioning: a study on patients with skin disease. J Psychosom Res 2007;62:223-229.

7. Lumley MA, Ovies T, Stettner L, Wehmer F, Lakey B. Alexithymia, social support and health problems. J Psychosom Res 1996;41:519-530.

8. Gupta MA, Gupta AK. Depression and suicidal ideation in dermatology patients with acne, alopecia areata, atopic dermatitis and psoriasis. Br J Dermatol 1998;139:846-850.

9. Linnet J, Jemec GB. An assessment of anxiety and dermatology life quality in patients with atopic dermatitis. Br J Dermatol 1999;140:268-272.

10. Baldwin HE. The interaction between acne vulgaris and the psyche. Cutis 2002;70:133-139.

11. Hayashi N, Akamatsu H, Kawashima M; Acne Study Group. Establishment of grading criteria for acne severity. J Dermatol 2008;35:255-260.

12. Dereboy İF. Alexithymia. Turkish J Psychiatry 1990;1:157-165.

13. Taylor GJ, Ryan D, Bagby RM. Toward the development of a new selfreport alexithymia scale. Psychother Psychosom 1985;44:191-199.

14. Richards HL, Fortune DG, Griffiths CE, Main CJ. Alexithymia in patients with psoriasis: clinical correlates and psychometric properties of Toronto Alexithymia Scale-20. J Psychosom Res 2005;58:89-96.

15. Taylor GJ, Bagby RM. New trends in alexithymic research. Psychother
Psychosom 2004;73:68-77.

16. Guilbaud O, Corcos M, Hjalmarsson L, Loas G, Jeammet P. Is there a psychoneuroimmunological pathway between alexithymia and immunity? Immune and psychological correlates of alexithymia. Biomed Pharmacother 2003;57:292-295.

17. Todarello O, Casamassima A, Daniele S, Marinaccio M, Fanciullo F, Valentino L, et al. Alexithymia, immunity and cervical epithelial neoplasia: replication. Psychother Psychosom 1997;66:208-213.

18. Corcos M, Guilbaud O, Paterniti S, Curt F, Hjalmarsson L, Moussa M, et al. Correlation between serum levels of interleukin-4 and alexithymia scores in healthy female subjects: preliminary findings. Psychoneuroendocrinology 2004;29:686-691.

19. Arck PC, Slominski A, Theoharides TC, Peters EM, Paus R. Neuroimmunology of stress: skin takes center stage. J Invest Dermatol 2006;12: 1697-1704.

20. Ito N, Ito T, Kromminga A, Bettermann A, Takigawa M, Kees F, et al. Human hair follicles display a functional equivalent of the hypothalamic-pituitary-adrenal axis and synthesize cortisol. FASEB J 2005;19: 1332-1334.

21. Slominski A, Wortsman J. Neuroendocrinology of the skin. Endocr Rev 2000;21:457-487.

22. Masmoudi J, Maalej I, Masmoudi A, Rached H, Rebai A, Turki H, et al. Alexithymia and psoriasis: a case-conrol study of 53 patients. Encephale 2009;35:10-17.

23. Consoli SM, Rolhion S, Martin C, Ruel K, Cambazard F, Pellet J, et al. Low levels of emotional awareness predict a beter response to dermatological treatment in patients with psoriasis. Dermatology 2006;212: 128-136.

24. Allegranti I, Gon T, Magaton-Rizzi G, Aguglia E. Prevalence of alexithymic characteristics in psoriatic patients. Acta Derm Venerol Suppl (Stockh) 1994;186:146-147.

25. Picardi A, Pasquini P, Cattaruzza MS, Gaetano P, Baliva G, Melchi CF, et al. Only limited support for a role of psychosomatic factors in psoriasis. Results from a case-control study. J Psychosom Res 2003;55:189-196.

26. Sayar K, Köse O, Ebrinç S, Çetin M. Hopelessness, depression and alexithymia in young Turkish soldiers suffering from alopecia areata. Dermatol Psychosom 2001;2:12-15.

27. Cordon Yazıcı A, Başterzi A, Tot Acat Ş, Üstünsoy D, Ikizoğlu G, Demirseren D, et al. Alopecia areata and alexithymia. Turkish J Psychiatry 2006;17:101-106.

28. Picardi A, Pasquini P, Cattaruzza MS, Gaetano P, Baliva G, Melchi CF, et al. Psychosomatic factors in first-onset alopecia areata. Psychosomatics 2003;44:374-381.

29. Picardi A, Pasquini P, Cattaruzza MS, Gaetano P, Melchi CF, Baliva G, et al. Stressful life events, social support, attachment security and alexithymia in vitiligo. A case-control study. Psychother Psychosom 2003; 72:150-158.

30. Smithard A, Glazebrook C, Williams HC. Acne prevalance, knowledge about acne and psychological morbidity in mid-adolescence: a community-based study. Br J Dermatol 2001;145:274-279.

31. Do JE, Cho SM, In SI, Lim KY, Lee S, Lee ES. Psychosocial aspects of acne vulgaris: a community-based study with Korean adolescents. Ann Dermatol 2009;21:125-129.

32. Kubota Y, Shirahige Y, Nakai K, Katsuura J, Moriue T, Yoneda K. Community-based epidemiological study of psychosocial effects of acne in Japanese adolescents. J Dermatol 2010;37:617-622.

33. Magin PJ, Pond CD, Smith WT, Watson AB, Goode SM. A cross-sectional study of psychological morbidity in patients with acne, psoriasis and atopic dermatitis in specialist dermatology and general practices. J Eur Acad Dermatol Venereol 2008;22:1435-1444.

34. Grahame V, Dick DC, Morton CM, Watkins O, Power KG. The psychological correlates of treatment efficacy in acne. Dermatol Psychosom 2002;3:119-125.

35. Montreuil M, Pedinielli JL. Parallel visual processing characteristics in healthy alexithymia subjects. Administration of the Toronto Alexi- 
thymia Scale and the parallel visual information test. Encephale 1995; 21:589-595.

36. Moriguchi $Y$, Maeda M, Igarashi T, Ishikawa T, Shoji M, Kubo C, et al.
Age and gender effect on alexithymia in large, Japanese community and clinical samples: a cross-validation study of the Toronta Alexithymia Scale (TAS-20). Biopsychosoc Med 2007;1:7. 